\title{
Dothi Etape: journey through the experiences of performance and art
}

\author{
S. A. Syed Albakri, S. S. Zubir, Z. Yahya, F. R. Razali \& F. Kholid \\ Centre of Studies for Architecture, Faculty of Architecture, \\ Planning and Surveying, Universiti Teknologi MARA, Malaysia
}

\begin{abstract}
In an ever-changing urban landscape, connectivity in terms of walkability is emerging as a major factor when considering urban design. When a city experiences rapid development, it also contributes to an increased homogenization of big city blocks. The acquisition of smaller buildings creates bigger and more modern blocks that not only cause gentrification in terms of population and commercial diversities but also decreases the permeability of streets. This will in turn reduce the walkability of the streets due to the limited numbers of corners and intersections a pedestrian can choose to follow. Rapid development causes the disappearance of historical enclaves where some of the major streets and pedestrianized areas lose their local streetscape identity. This theoretical urban design projection is located at Le Loi in district 1 of Ho Chi Minh City where there is the Municipal Theatre, the Saigon Tax Trade Centre and various avant-garde hotels that were constructed during the French colonial period. The site is also located perpendicular to the newly developed Ngu Yen Hue Boulevard with restrictions in creating any form of activities on this boulevard. To undermine these restrictions, a cultural catalyst approach is identified as the most suitable due to the prevalent nature of how the road becomes the hot spot for cultural activities such as the Lunar Flower Festival held every year. The site has the most cultural and heritage value and is made as the focal point of the design. Concepts are formulated to enhance the experiences of the site where nodes are established as main catalysts for connectivity. The generative concepts are based on the idea of the Situationists International where a bottom-up approach is preferred. These concepts are Derive, Detournment and Stage Cinematics. Translation of these concepts into the proposed schemes will at its core assist in the revitalization of the site by injecting an ever-changing routes and paths, allowing for increased
\end{abstract}


diversity in land-use, cultural activities and urban typologies respectively. These concepts will generate an ever-changing experience of the spaces throughout the year.

Keywords: performance arts, journey, derive, detourment, walkability, situationist, urban stage.

\section{Introduction}

Ho Chi Minh, better known to most as Saigon, is considered to be one of three major cities in Vietnam. The city itself has seen a dramatic rise in development and population growth. It has last since doubled its population from 4.6 million in the span of 20 years [1]. It is made up of 5 rural districts and 19 urban districts. Its CBD is currently located in District 1 and is duly replaced when the new development in District 2 is completed. The city is the highest in terms of density of population and is the main tourism hub in Vietnam. Vietnam has seen almost 4.3 million tourists a year with $70 \%$ of those visiting Ho Chi Minh City (HCMC) [2]. The attraction of the city still retains the French colonial influence in its architecture. Some of the attractions include the Revolutionary Museum, War Remnants Museum, $\mathrm{Cu}$ Chi Tunnels and the Saigon Municipal Theatre.

$\mathrm{HCMC}$ is made up of a mixture of centralized and grid system of city planning. Le Loi Road, one of the main roads in the city, is located in District 1 with many iconic attractions including the Municipal Theatre. This road is chosen as the study area due to the potential significance of the theatre in reinvigorating the place to its colonial ambiance. The Municipal Theatre acts as the catalyst on site capable of restoring the previously bustling road with a high volume of pedestrians. (Figure 1).

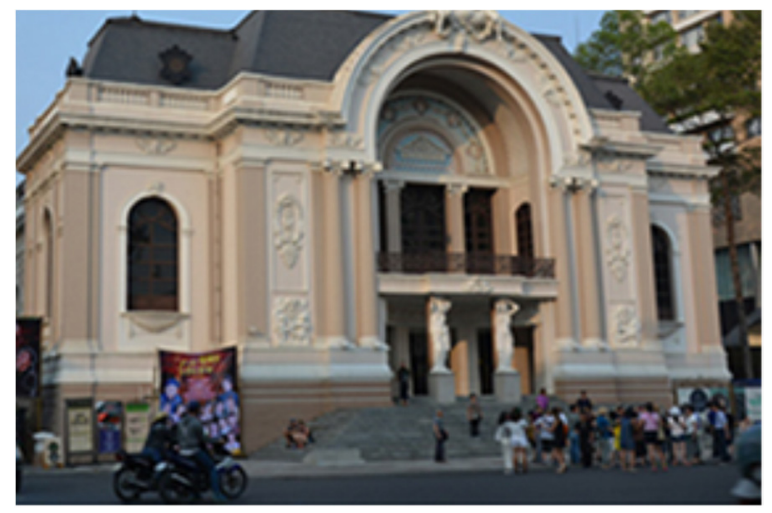

Figure 1: The Saigon Municipal Theatre.

\section{Site setting}

District 1 in Ho Chi Minh City is considered the CBD and in turn will have a high concentration of urban development in lieu of the expanding economy of Vietnam 
(Figure 2). Moreover, this increase in intensity of development has caused several issues to arise in the form of gentrification, homogenization of city blocks and the loss of its heritage buildings, that seem to be the main attraction for tourists to visit the city in the first place. The city has essentially lost its identity as the Pearl of the Orient and instead has given rise to capitalism. As Vietnam was previously a country tied by its socialistic roots, the recent influence of capitalism may have caused detrimental long term issues. The study area is near the boulevard in Le Loi road, where the Saigon Tax Trace Centre is located leading towards the Municipal Theatre. The existing site context include various hotels built during the French and American occupation such as the Continental Hotel, Rex Hotel, Tax Trade Centre, Caravelle Hotel, Union Square and the Municipal Theatre. The site is also located perpendicular to the newly developed Nguyen Hue Boulevard. While it is currently very high restrictions in creating any activities on this boulevard, the chosen site acts to undermine these restrictions by creating walkable streets on the perpendicular connected road. Adjacent to the site is the Dong Koi road aptly named fashion street and a few blocks away lies the textile tourist attraction, Ben Tanh Market.

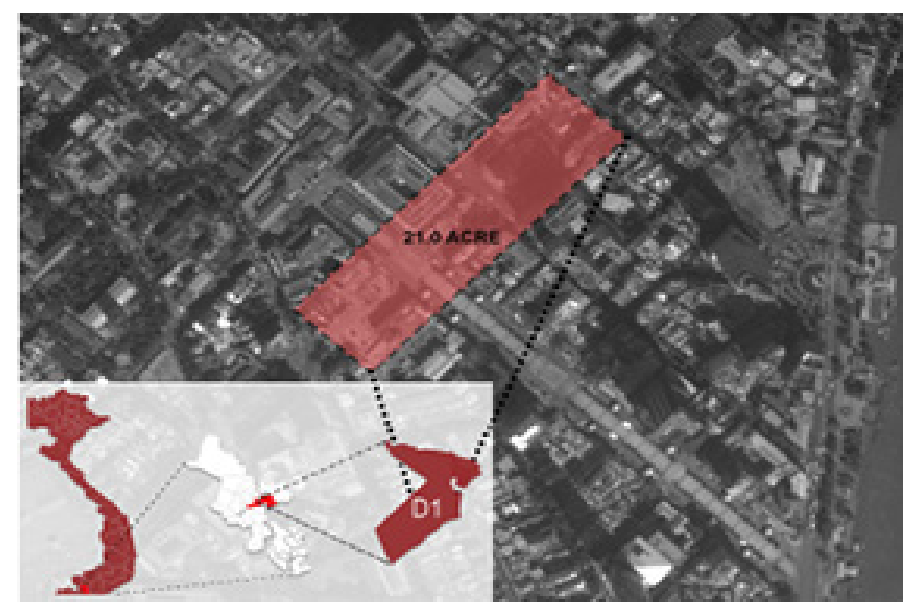

Figure 2: Study area of the site location in District 1, Ho Chi Minh City.

\section{Potentials and dilemmas}

Several dilemmas have been identified from the contextual analysis of the site. One of these include the predominantly high distribution of commercial land-use and lack of residential area. The area is dense with only commercial retail areas relegated to high-end shops and hotels. The number of visitors of medium and low income seem to be decreasing while the intended users seem to be ignoring these areas as well. The isolated society does not have the opportunity to naturally thrive and grow due to lack of diversified pedestrian traffic (Figure 3). There are 
staggeringly high numbers of 4-5 star hotels and a non-existent enclave of residential and service apartments [3].

Another dilemma is the absence of an adequate public realm. The area around the site has very little amount of green spaces. Most of the buildings consist of big commercial blocks, negating the growth of public realms. The boulevard, though created for people to utilize, is devoid of any public amenities or facilities to attract pedestrians throughout the day.

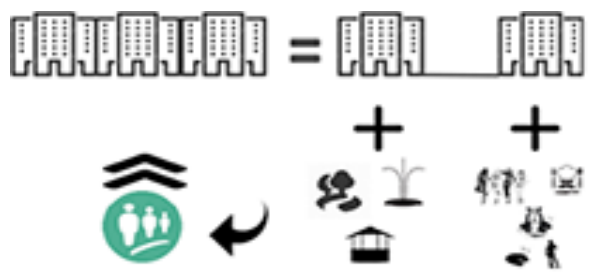

Figure 3: Importance of activities to improve quality of public realm.

Rapid development has also contributed to an increase in homogenisation of big city blocks. The acquisition of smaller buildings and shops that have led to the development of bigger modern blocks have not only caused gentrification in terms of population and commercial diversity but also has cause the permeability of streets to decrease and this will in turn reduce the walkability of the streets. Montgomery [4] mentioned that permeability can be defined and be seen more with smaller blocks due to the number of corner and intersection a pedestrian can chose to follow as opposed to a single route devoid of any choices.

The neglect on the Tax Trade Centre building has also been a big issue on this road. Mainly contested by the youths of the district due to its high nostalgic value, the building has seen countless changes to its façade but seemingly failed to revitalize the place and has since been shut down for redevelopment [5]. Though protests are still being made to preserve the building and its historic contents, positive results are yet to be seen (Figure 4).
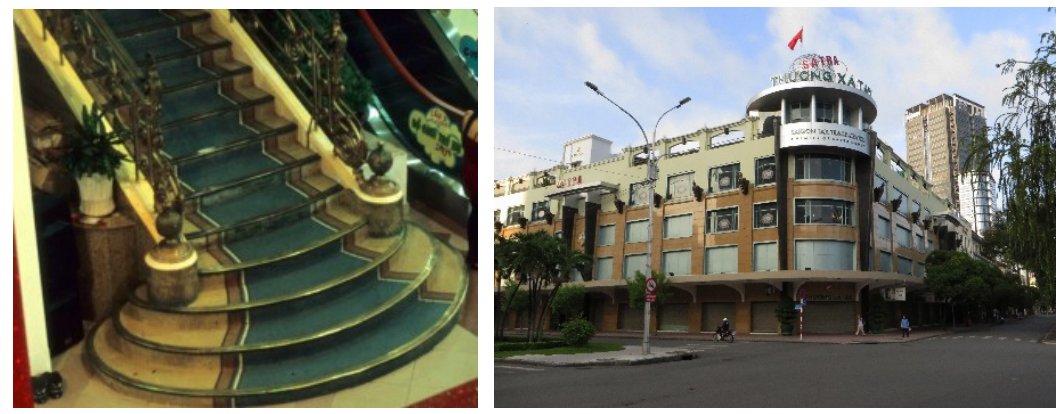

Figure 4: The Tax Trade Centre and its historic staircase. 
Potentials of the site include the forthcoming completion of the first metro subway in Ho Chi Minh City that will run in the middle of the study area. This subway will cater to all users with low ticket price of $4500 \mathrm{VND}$ that roughly translates to 20 cents in US currency per station. This will generate an additional of about 160,000 people per day to the study area [6]. Another potential is to diversify the commercial land-use in the area to cater for these new users. All range of shops that are previously there would have to be displaced to meet the everchanging demands of the growing economy of the place. The Municipal Theatre or the Opera House strategic location at the focal point of the area can be an added value in the revitalization and improve the imageability of the road as can be seen in figure 5 .

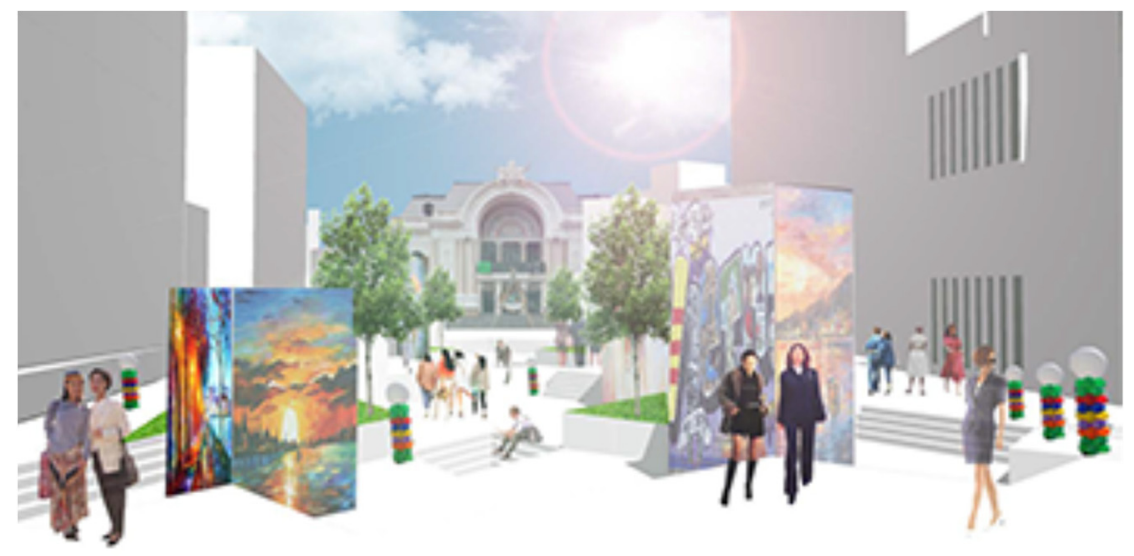

Figure 5: Focal axis point of the Municipal Theatre.

\section{Background theory}

The theory of the proposal centres around the idea to create a walkable street that has the Municipal Theatre as the main focus to enhance from in order to redefine the imagebility of the road as a cultural, heritage rich and liveable street.

Streets, like land use, can no longer afford to be single purpose [7]. This drives the proposal to create actual spaces that are worth traversing and looking on the streets themselves, essentially glorifying connectivity. This illustrates how people living their normal lives can be the focus of a street and how important it is to nurture natural activities native to the site. As highlighted by Peter Munford (in [8]), it is pertinent to experience local economy from the urban scene and drama as these are places where the mysteries of their hidden urban dimensions are kept. This proposal is also inspired from the Situationist City model that emphasizes in creating new spontaneous route choices and interchangeable spaces to suit different needs [9]. 


\section{Design statement}

Dothi Etape comes from the Vietnamese word Dothi meaning 'urban' and the French word Etape meaning 'stage'. In essence, Dothi Etape is a play on the idea of creating stages along streets to allow interaction and transaction where the urban scape, be it the users or the urban forms itself becomes the attraction of the space [10]. To achieve this idea, a situatuonist model is referred and three main concepts of Derive, Detournment and Stage Cinematics are chosen [11].

The proposed intervention is to create interchangeable generic blocks that allow the flexibility of activities to morph to changing times, culture and interest. The Opera House as the main catalyst generator of new innovative activities will incite and educate the public on urban heritage leading to the culmination of a more matured society. The idea of derive manifests in the creation of multiple choice routes that will allow the users to explore and experience [12]. The interchangeable space will also help in creating new experiences within the same space [13].

\subsection{Creating new and spontaneous journey}

The concept of derive from the situationist model is used to create a journey through the site [12]. The idea is to create many streets and corners via typology such as stage in the form of courtyard and to provide spaces looking into these courtyards to allow for activities such as people watching (as shown in figure 6).

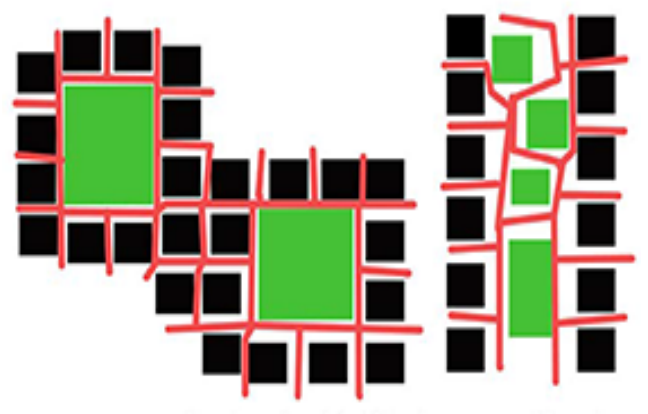

Figure 6: Courtyard allowing for different scenes to enhance the journey.

\subsection{Clashing of old to make new}

The concept of detournment enhances derive by creating new and ever changing spaces that allow the users to potentially walk through the same space and experience something new [14]. Generic blocks will allow the function of the spaces to change organically with various types of shops inhabiting the area. This area will be where most of the secondary programmes will be held such as cafés, restaurants, retail and commercial areas. Figure 7 shows the various activities to be introduced into the space. 


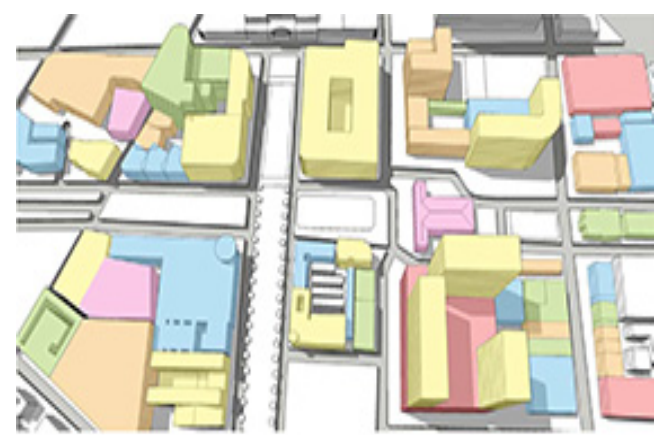

Figure 7: Existing land-use to be incorporated with newly introduced activities.

\subsection{Stage cinematics}

This concept allows the proposal to explore the idea of creating actual stage typologies and insert them where ever possible not only to allow for diversity of road paths but also to enhance the focal catalyst that is the Municipal Theatre. The main activities derived from this concept would be the performance arts and other outdoor activities that the community would conduct. This concept will allow for the creation of spaces that will naturally allow spectators a voyeuristic experience of performance art.

\section{Urban design strategies}

\subsection{Urban framework}

The proposal establishes the flexibility for the land-use of the place to change organically to suit the activities of the users. It will also allow for low-medium retail users to rent the spaces to increase diversity and to enhance the main parcel of the road with new activities to the site with the Opera House as the focal point. The streetscape design will inject richness and varieties of urban components to counter the monotonous design of the boulevard. Ribbons of open spaces as public realm will be extended to the levels above providing additional public spaces for people to exploit the views of the place. The idea of creating actual stage typologies and inserting them where ever possible not only allows for diversity of road paths but also to enhance the Municipal Theatre.

\subsection{Collision of spaces and blocks}

This strategy stems from the concept of detournment, an idea derived from the compendium of the Situationist International [12]. This concept refers to the idea of montage, where base understanding is to take a collection of something to transform it or give it a new purpose or meaning. This idea calls for the collision of land-use in the proposal, allowing for a diverse and fine-grained economy. 
In the context of this proposal, detournment is applied to the versatility of the blocks created. Generics blocks of the same area will be created to allow for the space to accommodate the generated main activity such as theatre performance to other secondary activities such as retails and cafés. This diversity and versatility of spaces will further enhance the routes created from the first strategy by allowing the spaces itself to change even when following the same route. This idea creates a space that will organically recreate new experiences (as shown in figure 8).

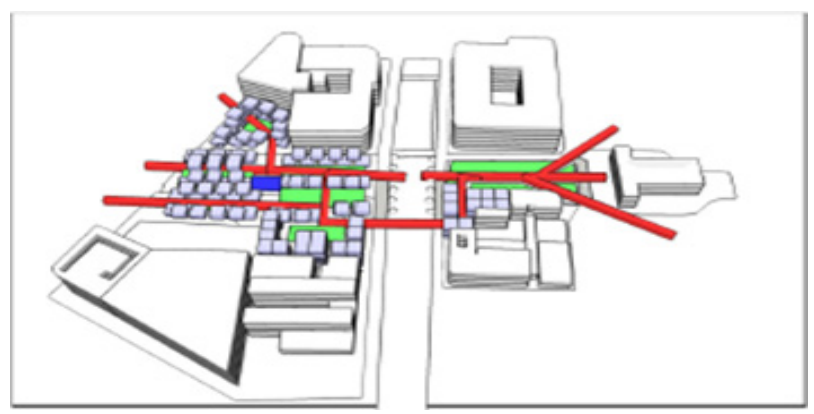

Figure 8: Strategy to create interesting space from generic blocks.

\subsection{Intensifying spontaneous routes}

This strategy is derived from the concept of derive where the idea is to create spontaneous journey through a diversity of street typology. The task is to create more corners and intersections where most interactions between users begin. These spaces are where pedestrians stop to enjoy the view created or stop to turn to a new direction. The concept also refers to the idea of creating an area which users can drift and wonder. This means creating web of streets and routes that will entice the user to continue walking and explore.

This strategy aims to include various types of roads to allow the creation of diverse corners, intersection and meandering routes to eliminate the characteristic of linearity as can be seen in figure 9 .

\subsection{Cinematics of the art culture}

This strategy is formed by concept that ultimately aims to introduce new activities to the area based on the determined main catalyst of the road, the Opera House. The idea to introduce highly cultural and art based activities to increase local interest is based on the prevalent interest of festivals that contributes to high influx of users to the area. Although these activities are yearly events, this strategy aims to add activities that run all year long to further invigorate the place.

The strategy itself takes art as the main focus and introduces all activities relevant to Vietnam. These activities will be zoned into several parcels that include a music zone, performance zone, gaming development zone and traditional arts zone (as shown in figure 10). Zones are used to create themes rather than relegate a parcel to a certain type of land-use. 


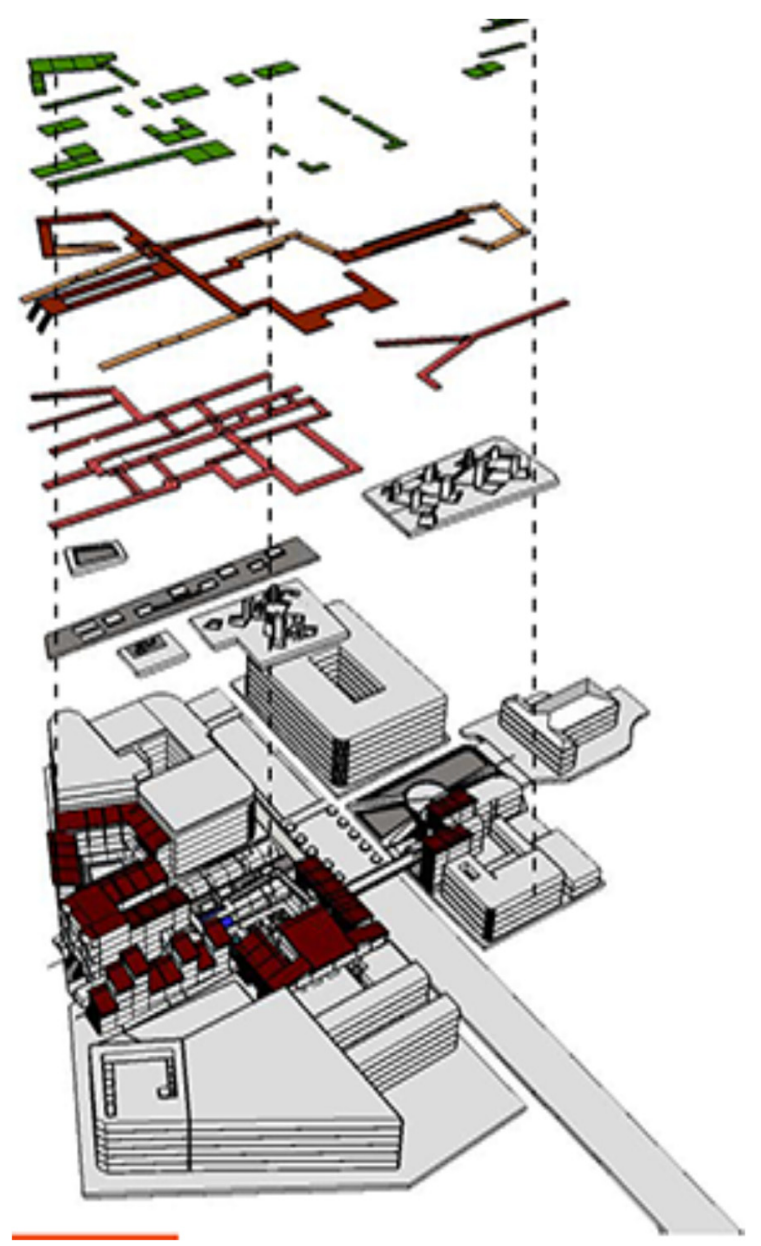

Figure 9: Strategy to create new interesting routes.

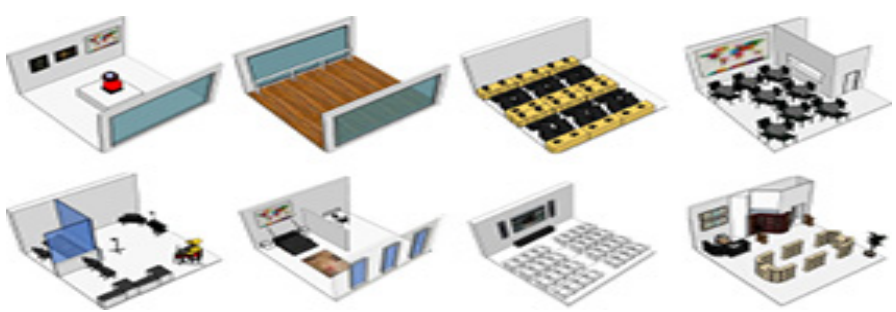

Figure 10: Strategy to create interesting activities from generic blocks. 


\subsection{Hypothetical typology}

The typologies that are explored are the generic blocks that are arranged conceptually according to the stages of performances such as coliseum and concert stage. These spaces will reflect on what the zones are. For example, the coliseum style of stage is most suitable for the introverted nature of gaming development. Although with it tries to emphasize the introvertedness of that zone, the courtyard that represents the stage invites users into the space. This in fact reverses the conventional planning of public spaces on the outside and private on the inside.

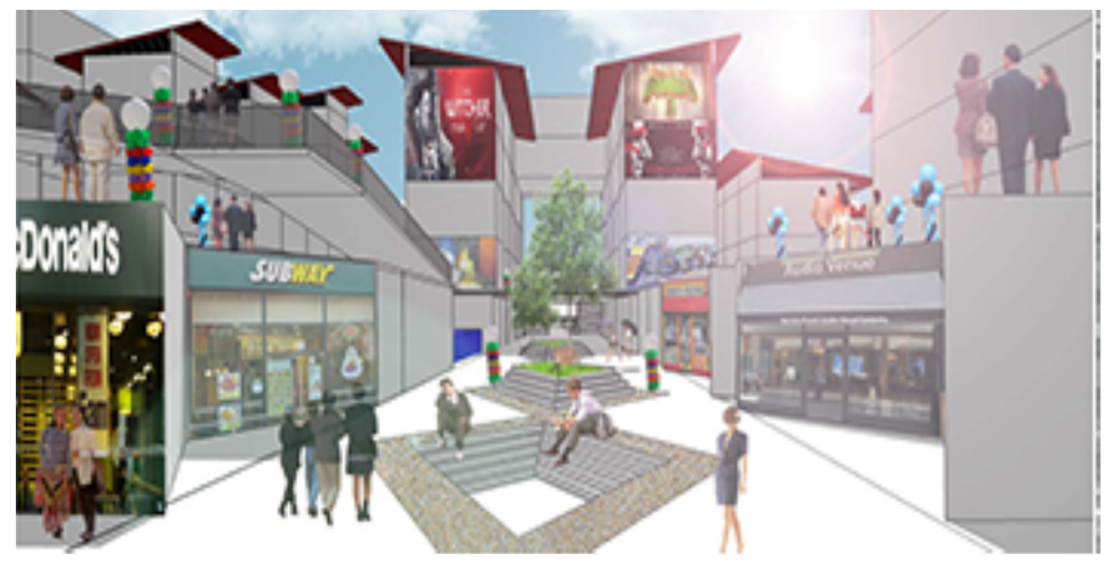

Figure 11: Main space leading to the Opera House.

Another notable typology is for the performance zone where the spaces that is in front of the Opera House is kept to a low height as seen in figure 11. This is to keep the focal point from the music zone towards the Opera House. These spaces are very suitable for public indoor spaces such as exhibition halls and art galleries. The outdoor typology will further enhance the spaces within to further allow more seating from outdoor to look inside. There is also a myriad of spaces on the floors above that allow the spectating of various other activities such as the outdoor movie screening.

\section{Conclusion}

The proposal acts to inspire and entice people by creating a journey of arts and cultural experience of the place to its former glory. The Opera House as the main catalyst and generator of events on the main street of Le Loi will be the icon. With the imminent arrival of users from the new subway metro, new spaces will be provided to accommodate all users ranging from low to high-income earners. In addition, the proposal acts to slow down the emerging typologies of big city blocks that are not responsive to local urban history, culture and context. These smaller, 


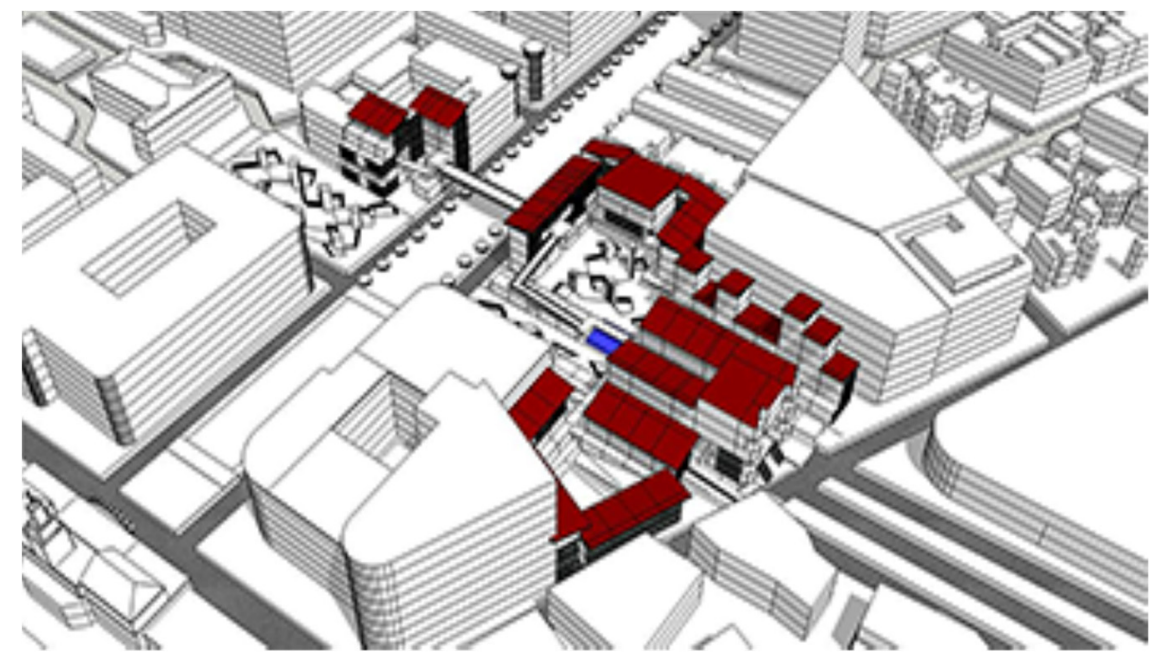

(a)

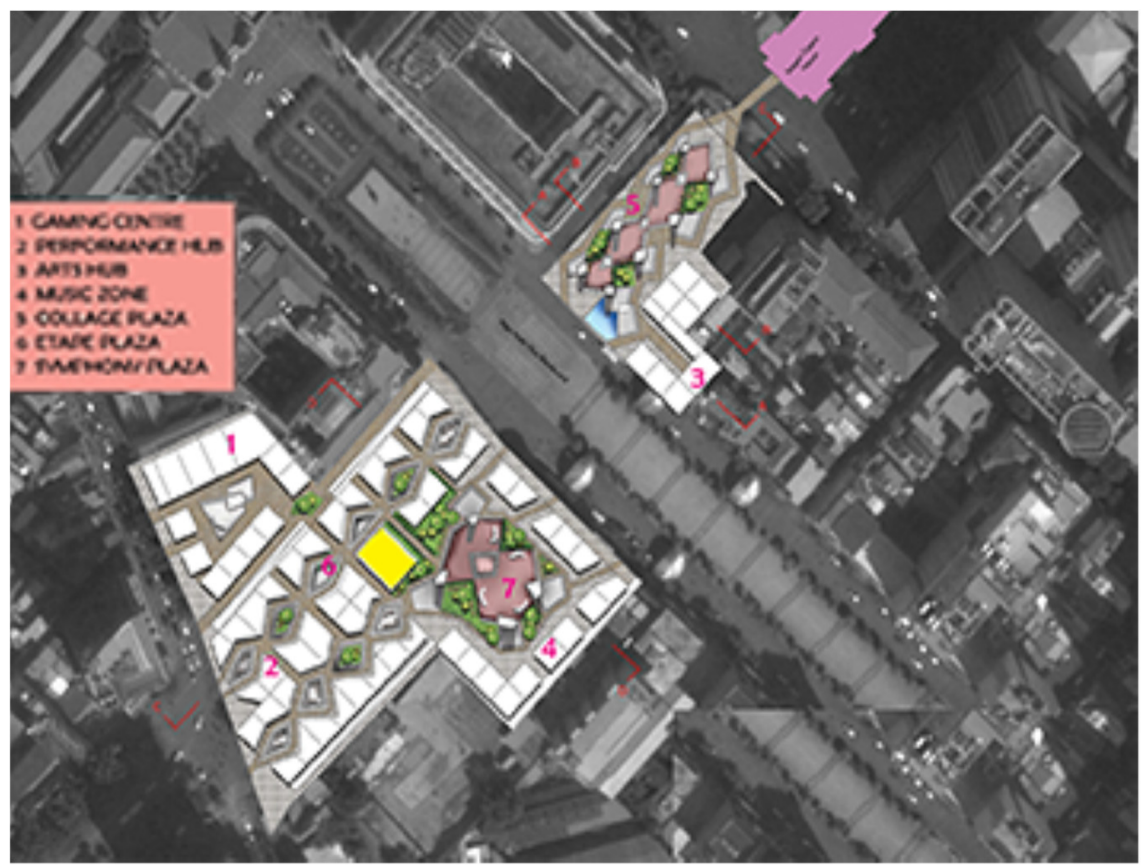

(b)

Figure 12: (a) Overhead view of proposed development; (b) Overall site plan of proposed development. 


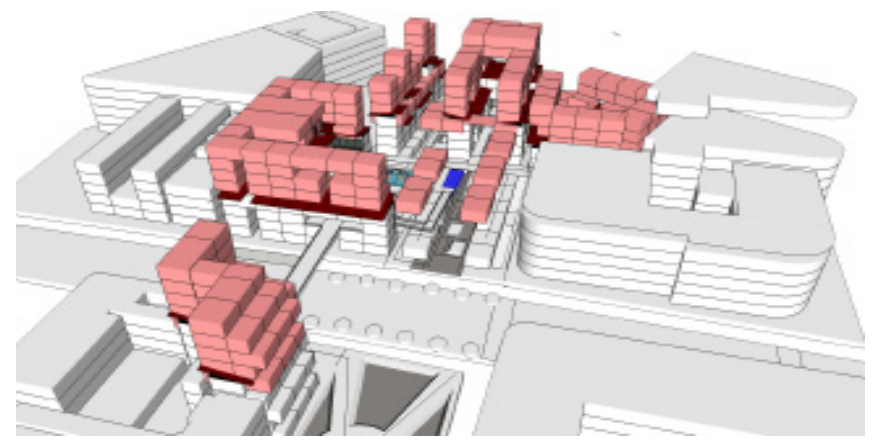

Figure 13: Art Academy proposal above existing massing.

diverse and versatile blocks will promote a fine grain economy and also contribute in combating the boredom of traversing the same space at different time. This will in turn improve the imageability of the road that will in turn increase its walkability. When diverse users and providers are able to thrive through an organic growth process, it is then that the space can be a self-sustaining utopia of urban living.

\section{Acknowledgements}

We would like to extend our utmost appreciation to the Faculty of Architecture, Planning and Surveying and the Institute of Graduate Studies, UiTM in providing a grant for the realization of this paper.

\section{References}

[1] Statistics Office of Vietnam, Statistics of Vietnam. available at http:/www.gso.gov.vn/default.aspx?tabid=387\&idmid=3\&ItemID=12873 [Accessed: 6 June 2016]

[2] Thong Tin Thuong Mai, The Population on Ho Chi Minh City, 2015. available at http://tinthuongmai.vn/IWINews.aspx [Accessed: 5 June 2016]

[3] Collier International, "Ho Chi Minh CBD Market Report", Collier International, 2015. [Accessed: 6 June 2016]

[4] Montgomery J., Making a city: Urbanity, Vitality and Urban Design, Journal of Urban Design, pp. 93-116, 1998.

[5] "Saigon Tax Trace Centre", 2010. extracted from http://www.historic vietnam.com/saigon-tax-trade-centre/ [Accessed: 6 June 2016]

[6] "Ho Chi Minh City Metro Plan", International Railway Journal, January 2001 [Accessed: 6 June 2016]

[7] Calthrope P., The urban network: A new framework for growth. Calthrope and Associates., 2002. From http://www.calthrope.com [Accessed: 6 June 2016] 
[8] Makeham P., Performing the City, Theatre Research International vol. 30m, International Federation of Theatre Research, pp. 150-160, 2005.

[9] Sadler S., "The Situationist City", The MIT Press, Cambridge, Massachusetts, 1998.

[10] The rooftop project: the neighbourhood, the rooftop project, 2015. Available at: http://www.the-neighbourhood.com. [Accessed: 6 June 2016]

[11] Montague L., Situationist City available at http://www.rudi.net/ node/22173 [Accessed: 6 June 2016]

[12] McDonough T., Guy Debord and the Situationist International: Texts and Documents, MIT Press, 2004.

[13] Hajjar M., The Situationist City: How the Situationist International Reinvented the City with Derive, Detournment and Unitary Urbanism, Washington University Research Digest, 2010.

[14] Plant S., The Most Radical Gesture: The Situationist International and After, Routledge, 1992. 